\title{
Review of Famous figures and diagrams in economics, edited by Mark Blaug and Peter Lloyd. Cheltenham: Edward Elgar, 2010, $468 \mathrm{pp}$.
}

\author{
LOÏC CHARLES \\ University of Reims \\ Institut National d'Études Démographiques \\ EconomiX, University of Paris Ouest \& CNRS
}

This thick volume brings together 58 short articles or entries on the theme of diagrammatic exposition in economics. The book is divided into three parts, and is opened by a significant introduction of about twenty pages in which the two editors provide an overview of the general spirit in which the book was conceived and produced, as well as a short history of the use of figures and diagrams in economics. In the latter, they give some insights into periods-that is, basically, pre-1870-that are not covered in the book, which focuses on modern economics. Following the introduction, there is an interesting appendix that lists curves/diagrams in chronological order of their "discovery", together with the name of the first economist to draw them (pp. 20-23).

Part I discusses figures used in a partial equilibrium setting and makes up about half the entries (28/58). These are in turn separated into three themes: "basic tools of demand and supply curve analysis", "welfare economics", and "special markets and topics". Part II is centred on "general equilibrium analysis" (17 entries) and divided into the themes of "basic tools" and "open economies" (i.e., international trade theory). Part III explores figures used in macroeconomic theory (13 entries). The first theme is "macroanalysis and stabilization"-a title which I found slightly awkward for entries that are almost all (8/9) dedicated to macroeconomic equilibrium diagrams of one kind or another. ${ }^{1}$ The second theme is "growth, income distribution and other topics".

Reading this book certainly provides interesting insights on a number of aspects related to the use of geometry in modern economics. However, as an historian of economics who has developed an interest in

\footnotetext{
${ }^{1}$ By the way, I am of the opinion that it would have been more accurate to classify the Laffer curve under growth and income distribution than macroanalysis.
} 
visual representations in economics I must say that I have been disappointed. Some entries provide absolutely no historical background. Most of them adopt the awkward procedure of presenting the history of the figure in the last section, which gives the impression that this was a kind of afterthought that has nothing to do with the analytical developments linked to the figure(s). Moreover, these short 'historical' abstracts are mainly concerned with providing a chronological time-line and giving the names of the economists who contributed to each diagram/theory. They therefore fall short of any real historical inquiry, though they may provide a useful guide for those who are willing to invest some time in a more historical type of reconstruction.

I must immediately qualify this judgment because it is somewhat unfair to the editors (and authors) who make it clear that the aim of the volume is not only or even primarily historical. Its first aim is "to provide an account of the role of each of the chosen figures and diagrams in economic analysis" (p. 1). This point is clearly underlined by the fact that the editors commissioned a significant number of noted theoreticians to discuss figures they themselves had either developed or helped to inscribe into theoretical debates, including William Baumol, John Chipman, Avinash Dixit, Nanak Kakwani, Anne O. Krueger, Richard Lipsey, or Yew- Kwang Ng. ${ }^{2}$

One thing that struck me is the similarity and sometimes even strict replication that one finds in some of the microeconomics and international economics diagrams. ${ }^{3}$ In some cases the same figure(s) - differentiated only by their captions and surrounding textcan mean something completely different from an economic point of view. It seems to me that this fact underlines the highly abstract character of some if not most of the diagrams used by modern economists, as well as their fundamentally illustrative character. The large majority of the diagrams which are presented do not contain a specific meaning by themselves; they are just useful aids to present a theory or some of its aspects.

\footnotetext{
${ }^{2}$ This preference for theoreticians may be criticized in at least one case: Kakwani's contribution on the Lorenz curve is of limited interest and might have been done better by someone else, such as Derobert or Thierot (who have written a nice historical and methodological article on the subject, see Derobert and Thierot 2003). This reminds us that the theoretician is not necessarily the person best able to provide a methodological or historical reflection on the figures that he created or helped to create.

${ }^{3}$ Compare, among other examples the 'utility-possibility frontier' (entry 34) and the 'phase diagram technique for analyzing the stability of multiple-market equilibrium' (entry 37); or the Stolper-Samuelson box (entry 40) and Edgeworth box one (entry 31).
} 
This point is further underlined by the fact that in several entries, the source of the diagram printed is not given and the author introduces it in very general terms, as on page 44 where one diagram is captioned simply as "an indifference map". In that case, due to the simplicity of the figure, there is probably little reason to argue with such a procedure. In other instances, I am not sure that the reader does not in fact lose much information by this off-hand approach. Let us take for example figure 5.1, "Hicks decomposition" (p. 59). The author of the entry, Hans Haller, mentions in passing that "a figure similar to Figure 5.1 is already contained in Mosak (1942, Fig. 2)". Well, what does "similar" mean here? Is it that a new figure has been produced to evade copyright issues? Or are there significant differences between figure 5.1 and Mosak's and, if so, are they mostly visual or do they involve as well some variance at the theoretical level? Likewise in many entries, we are told that the figure given is the "typical textbook presentation". ${ }^{4}$ In another case, we are presented with an 'updated' version of an historical diagram (entry 16).

The point I want to make here with all these examples is that in most of the entries, the precise source of the figure or its visual details do not matter that much for the author(s). They want to discuss the theories that the diagram illustrates, not the figure itself. Such an attitude casts a shadow over the whole project of the book. What is the point of collecting all these figures and diagrams if most of the text is in fact dedicated to presenting and discussing the theory? To put it bluntly, I believe that a more appropriate title would have been: A compendium of economic theories which have been illustrated by famous figures and diagrams. This title would have better expressed both the qualities and the limits of the book before us. On the other hand, I am not sure that it would be the right way to create a public for this book.

Let me end on a positive note. The entries are-as one would expect-quite diverse both in style and in content. As judgments in this regard are always subjective and depend a lot on one's personal interest, I will simply mention one that strikes me as particularly worthy of the attention of readers: the entry on the Fleming-Mundell diagram (no. 48). In their very subtle and detailed historical reconstruction of this diagram, Russell Boyer and Warren Young have been careful to compare

\footnotetext{
${ }^{4}$ See, among other examples, entries 8, 13, and 15 .
} 
the figure and the theory systematically. What I found particularly interesting is that they point out instances where the two differed in significant ways. Indeed, their article shows how intricate the analysis can be when one considers the evolution of the figure and the theory (equations and text) in parallel rather than from the perspective of only one of them. It seems that the history of the Fleming-Mundell diagram might be one these cases where the figure itself played a role in the dynamics of a theory's evolution.

\section{REFERENCES}

Derobert, Laurent, and Thieriot, Guillaume. 2003. The Lorenz curve as an archetype: a historico-epistemological study. The European Journal of the History of Economic Thought, 10 (4): 573-585.

Loïc Charles is professor of economics at the University of Reims Champagne Ardenne (URCA), researcher at the Institut National d'Etudes Démographiques (INED), and EconomiX (University of Paris Ouest and CNRS/UMR 7235). He has worked and published on eighteenth-century French economics and economic history as well as the history of visualization in social sciences.

Contact e-mail: <charles@ined.fr> 